J. Lake Sci. (湖泊科学) , 2022, 34(2): 569-581

DOI 10. 18307/2022. 0217

(c) 2022 by Journal of Lake Sciences

\title{
网围拆除后东太湖鱼类功能群时空变化及影响因子
}

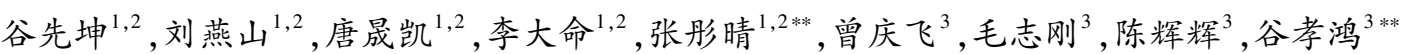 \\ (1: 江苏省淡水水产研究所,南京 210017$)$ \\ (2: 江苏省内陆水域渔业资源重点实验室,南京 210017) \\ (3: 中国科学院南京地理与湖泊研究所,南京 210008)
}

\begin{abstract}
摘 要: 通过 2019 年 4、7、10 月对网围拆除后东太湖原网围养殖区和非养殖区鱼类资源的调查监测,构建“营养一运动” 复合功能群, 分析探讨鱼类功能群的时空分布特征及其与环境因子的关系. 结果表明: 网围拆除后东太湖鱼类群落监测 到 39 种,鲤科鱼类占比 $66.67 \%$, 与太湖相当 $(66 \%)$. 采集到的鱼类可构建为 4 个营养功能群和 5 个运动功能群, 共计 11 个复合功能群, 其中 “杂食性一纺锤体型且运动能力强”功能群占比最大, 比例为 $41.34 \%$; 其次为 “初级肉食性一纺锤体型 且运动能力强” “植食性一纺锤体型且运动能力强” “次级肉食性一纺锤体型且运动能力强” 功能群, 占比分别为 $28.70 \% 、 13.46 \% 、 13.40 \%$, 其他功能群占比较少. 在季节变化上, $4-10$ 月, 原网围养殖区一直以“杂食一强纺锤”鱼类功能 群为主, 非养殖区则是从 “杂食性一纺锤体型且运动能力强” + “植食性一纺锤体型且运动能力强” 功能群为主向 “初级肉 食性一纺锤体型且运动能力强”功能群为主演变; 空间分布上原网围养殖区杂食性、次级肉食性、植食性鱼类功能群密度 大于非养殖区, 初级肉食性功能群密度小于非养殖区. 环境因子中氨氮是影响原网围区鱼类功能群结构分布的显著影响 因子, 且与所有鱼类功能群分布呈负相关. $\mathrm{pH}$ 、总磷、总氮、溶解氧等也是影响鱼类功能群分布的主要环境因子, 但其影响 并未达到显著水平. 鱼类功能群分析表明网围拆除对东太湖鱼类群落恢复及生态系统修复具有积极作用, 但仍需对网围 拆除后鱼类群落及自然环境的演变规律进一步探讨和分析.
\end{abstract}

关键词: 功能群;鱼类群落;时空分布; 影响因子;东太湖;网围拆除

\section{Spatio-temporal variation with influencing factors for fish functional groups in East Lake Taihu after the net removal *}

Gu Xiankun ${ }^{1,2}$, Liu Yanshan ${ }^{1,2}$, Tang Shengkai ${ }^{1,2}$, Li Daming ${ }^{1,2}$, Zhang Tongqing ${ }^{1,2 * *}$, Zeng Qingfei $^{3}$, Mao Zhigang $^{3}$, Chen Huihui ${ }^{3} \&$ Gu Xiaohong ${ }^{3 * *}$

(1: Freshwater Fisheries Research Institute of Jiangsu Province, Nanjing 210017, P.R. China)

(2: Key Laboratory of Fisheries Resources in Inland Water of Jiangsu Province, Nanjing 210017, P.R. China)

(3: Nanjing Institute of Georgraphy and Limonology, Chinese Academy of Sciences, Nanjing 210008, P.R.China)

Abstract: Based on the investigation and monitoring of fish resources in the original net enclosure (ONE) and no net enclosure ( NNE) areas of East Lake Taihu after the removal of net enclosure (RNE) in April, July and October 2019, the “trophic-locomotion" combined functional group was constructed, and their spatio-temporal distribution characteristics and their relationship with environmental factors were analyzed. The results showed that 39 species of fish were detected in East Lake Taihu after the RNE, and the proportion of Cyprinidae fish was $66.67 \%$, which was similar to that in Lake Taihu ( 66\%). The collected fish could be divided into 4 trophic and 5 locomotion groups, with a total of 11 combined groups, among which the group “omnivorous, spindle body type with the strong locomotor ability" accounted for the largest proportion (41.34\%). The followed functional groups were “primary carnivorous-spindle body type and strong locomotor ability”, “plant carnivorous-spindle body type and strong locomotor a-

* 2021-02-05 收稿; 2021-08-03 收修改稿.

江苏省省级单位农业项目 (2020-SJ-016-2)、国家重点研发计划项目 (2020YFD0900305)、江苏省太湖水环境综合治 理科研课题项目 (TH2018303) 和江苏省自主科研项目 (BM2018027-SZL201905) 联合资助.

** 通信作者; E-mail: zhtq3@126.com;xhgu@ niglas.ac.cn. 
bility”, "secondary carnivorous-spindle body type and strong locomotor ability”, accounting for $28.70 \%, 13.46 \%$ and $13.40 \%$, respectively. In terms of seasonal change, the “omnivorous, spindle body type with strong locomotor ability” group was dominant in the ONE, while in the NNE, the dominant functional group evolved from "omnivorous-spindle body type with strong locomotor ability" + "herbivores-spindle body type with the strong athletic ability" to "primary carnivorous-spindle body type with the strong locomotor ability". Spatially, the density of omnivorous, secondary carnivorous and herbivorous fish in the ONE was higher than that in the NNE, while the functional group density of primary carnivorous fish was lower than that in the NNE. Among the environmental factors, ammonia nitrogen was the significant factor affecting the distribution of functional groups of fish in the ONE and was negatively correlated with the distribution of all functional groups. $\mathrm{pH}$, total phosphorus, total nitrogen and dissolved oxygen were also the main environmental factors, but not significantly affecting the distribution of fish functional groups. The RNE has a positive effect on the restoration of the fish community and ecosystem remediation in East Lake Taihu. However, the evolution of the fish community and the natural environment after the RNE still needs to be further assessed.

Keywords: Functional groups; fish community; spatio-temporal distribution; influencing factors; removal of the net enclosure; East Lake Taihu

东太湖 ( $30^{\circ} 58^{\prime} \sim 31^{\circ} 07^{\prime} \mathrm{N}, 120^{\circ} 25^{\prime} \sim 120^{\circ} 35^{\prime} \mathrm{E}$ ) 位于太湖东南部, 湖区面积 $185.4 \mathrm{~km}^{2}$, 其中水面面积 $134.90 \mathrm{~km}^{2}$. 东太湖是太湖网围养殖的主要集中区, 养殖面积从 $113.45 \mathrm{~km}^{2}$ 不断压缩至 $30 \mathrm{~km}^{2[1]}$. 为了保护 东太湖水质, 恢复养殖区原有生态面貌, 修复受损生态系统 ${ }^{[2]}, 2019$ 年 5 月底前东太湖完成了所有网围的拆 除工作. 网围拆除后, 生物多样性恢复过程及受损生态系统的修复效果是东太湖环境保护工作的关注重点.

鱼类群落被广泛应用于河流、湖泊生态监测与评价 ${ }^{[3]}$, 而鱼类功能群是近年来逐渐兴起的研究生物与 环境相互关系的生态学方法之一. 鱼类功能群的研究主要是依据鱼类的生物学与生态学信息 (营养、栖息 地、生活史、形态等) 研究环境因素与功能群之间的相互作用 ${ }^{[4]}$. 与物种多样性相比, 鱼类功能群与生境的 相关性较群落结构则更为紧密, 对环境因子的变化更为敏感, 因此鱼类功能群的划分能更加准确和客观地 表现出鱼类与环境变化的关系 ${ }^{[5-6]}$. 国外学者研究认为鱼类功能群结构及其多样性可以反映气候、水文条件 等环境因素的变迁 ${ }^{[7]}$ : 如河流上建筑大坝导致大坝下游自然流量减少, 而鱼类群落则呈现功能简化特 征 ${ }^{[6,8]}$; 气候变化导致河流中的鱼类本地物种灭绝, 外来物种的人侵, 土著种减少和外来种增加造成群落结 构和功能的重组 ${ }^{[9]}$. 国内对鱼类功能群的研究处于起步阶段, 目前主要集中于海洋和河流生态系统. 鱼类的 季节性洄游移动是海洋鱼类营养功能群变化的主要影响因素 ${ }^{[10-13]}$; 而土地利用、河道治理等人类活动会降 低河流鱼类功能群的多样性并改变其群落结构 ${ }^{[14-16]}$. 关于湖泊鱼类功能群的研究相对较少, 湖泊鱼类功能 群的组成及多样性可能会随着湖泊水位变化、网围养殖等环境因素或者人为干扰因素而改变, 例如浅水湖 泊中水位下降 $1 \mathrm{~m}$ 会导致除肉食性鱼类外的其他鱼类生物量显著减少 ${ }^{[17-18]}$.

作为太湖主要的网围养殖区, 之前对东太湖的研究多集中于养殖模式、养殖容量的探讨及其对水质、水 生植被、底质等环境因素的影响 ${ }^{[19-21]}$, 而对东太湖的鱼类群落的关注很少, 仅有李云凯等 ${ }^{[22]}$ 曾经在东太湖网 围养殖区外人湖口附近调查监测到鱼类 8 种. 网围拆除后, 人类活动干扰消失, 东太湖水质环境以及水生生 物结构必然发生重大变化, 因此研究网围拆除后东太湖鱼类功能群结构及其对环境变化的响应具有重要意 义. 本研究以东太湖为研究对象, 应用功能生态学方法分析网围拆除后东太湖鱼类功能群时空分布特征, 并 探讨鱼类功能群结构变化与环境因子的相互关系, 以期为东太湖的环境治理和生态修复提供参考依据.

\section{1 材料与方法}

\section{1 调查站位设置与调查方法}

分别于 2019 年 $4 、 7$ 和 10 月, 在东太湖设置 4 个采样点 (图 1) 进行渔获物采集, 同时监测水质的理化指 标. S1、S2 为原网围养殖区, S3、S4 为非养殖区. 2019 年 4 月采样时东太湖网围水面以上部分已全部拆除, 但 水面下的底部围栏依然存在. 7、10 月采样时网围已全部拆除. 渔获物采集以刺网和地笼为主, 每样点放置多 目刺网 1 条和地笼 3 条. 多目刺网网目大小 $1 \sim 5$ 指 (即网目大小分别为 $2 、 3 、 4 、 7 、 10.5 \mathrm{~cm}$ ), 每个网目分别长 $60 \mathrm{~m}$, 共长 $300 \mathrm{~m}$. 地笼网目规格 $0.9 \mathrm{~cm}$, 全长 $20 \mathrm{~m}$. 刺网和地笼均于前一天下午 $6: 00$ 左右下网放置于采样 点附近水域, $12 \mathrm{~h}$ 后即第二天上午 $6: 00$ 左右收网采集渔获物. 对所采集的鱼类进行鉴定分类、称量和计数. 
鱼类的学名、分类地位及生态类型等以《太湖鱼类志》 ${ }^{[23]}$ 、《江苏鱼类志 $\rangle^{[24]}$ 为主要依据. 根据《内陆水域渔 业自然资源调查手册》 ${ }^{[25]}$ 鱼类资源密度以单位努力量捕捞量表示 (catch per unit effort, CPUE), 本研究中以 每 12 小时每网捕捞渔获物尾数计 (ind./( net·12 h) ).

采集渔获物的同时, 利用哈希 HQ40D 多参数水质检测仪监测水温 $(\mathrm{T})$ 、溶解氧 ( DO ) 、 $\mathrm{pH}$ 等, 记录水深、 透明度 $(\mathrm{SD})$, 同时采集水样在实验室分析总磷 $(\mathrm{TP})$ 、总氮 $(\mathrm{TN})$ 、氨氮 $\left(\mathrm{NH}_{3}-\mathrm{N}\right)$ 、硝态氮 $\left(\mathrm{NO}_{3}^{-}-\mathrm{N}\right)$ 、磷酸盐 $\left(\mathrm{PO}_{4}^{3-}-\mathrm{P}\right)$ 、高锰酸盐指数 $\left(\mathrm{COD}_{\mathrm{Mn}}\right)$ 、和叶绿素 $a(\mathrm{Chl} . a)$ 等指标浓度, 样品的采集、保存及分析参照 $《$ 内陆水域 渔业自然资源调查手册》进行 ${ }^{[25]}$.

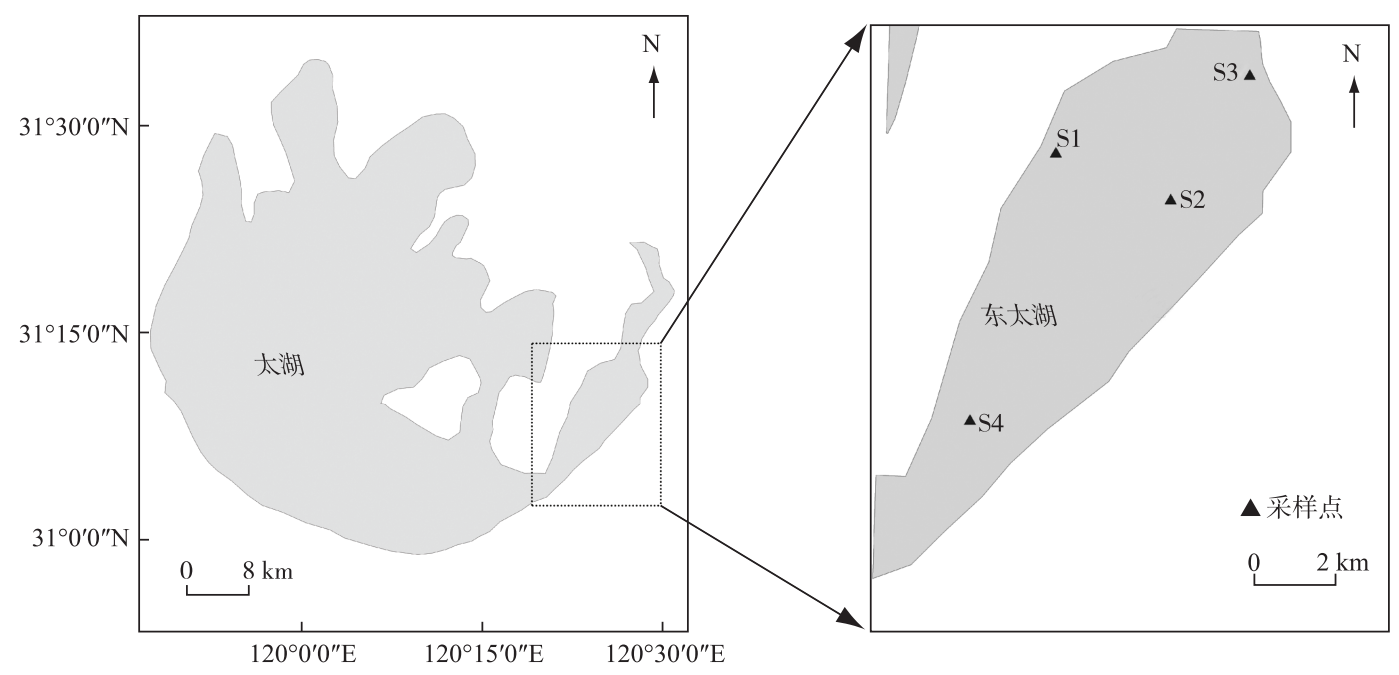

图 1 东太湖采样点位分布

Fig.1 Distribution of sampling locations in East Lake Taihu

\section{2 功能群构建}

在物种分类的基础上, 利用 FishBase 数据信息并结合相关文献、《江苏鱼类志》、《太湖鱼类志》等资料, 确定每物种的食性, 分为次级肉食性鱼类 (以小型鱼类为食)、初级肉食性鱼类 (以浮游动物、底栖动物、水 生昆虫等无脊椎动物为食)、杂食性鱼类 (兼食无脊椎动物、植物以及腐屑)、植食性鱼类 ( 以藻类、水生维管 束植物为食) 共 4 个营养功能群 (trophic group, TG).

参照 Poff 和 Allan ${ }^{[7]}$ 的方法, 使用 2 个比值性状反映鱼类的运动功能特征, 即体高/体长和最大尾鯺 高/最小尾柄高, 前者反映的是鱼体的体形, 即水动力学轮廓特征; 后者反映的是鱼类的游泳能力大小, 比值 越大, 游泳能力越强. 基于每物种的上述 2 组功能性状数据, 构建种间的 Bray-Curtis 相似性矩阵, 运用 Primer 软件中的 Cluster 聚类分析来确定鱼类物种的不同运动功能群 (locomotion group, LG) 类型. 根据每物 种的食性和运动功能群, 最终确定其“运动 - 营养”复合功能群 (combined group, CG) 类型.

\section{3 数据整理与分析}

将每个站点每月收集到的刺网和地笼中的鱼类数量作为一个样本来进行数据分析, 分析前对原始数据 进行 $\log (x+1)$ 对数转换, 将前面划分的每个功能群当做一个物种, 同一功能群内物种合并视为一个“功能群 大种”, 得到“功能群×样点”矩阵. 利用 Primer5.2 软件, 采用双因子交互相似性分析 (Two-way ANOVA) 研究 原网围养殖区与非养殖区之间的功能群组成的差异显著性 ${ }^{[8]}$, SIMPER 相似性百分比分析鱼类功能群结构 的不同月份之间组内相似性的贡献率. 采用 CANOCO 4.5 软件对各月份的鱼类功能群数量组成和环境因子 进行梯度分析, 首先将各样方的功能群鱼类数量组成数据取对数后进行去趋势对应分析 (DCA), 根据分析 结果中各排序轴长度决定排序的模型, 由于排序轴长度均小于 3 , 选择线性模型的主成分分析 (PCA) 和圥余 分析 $(\mathrm{RDA})$ 两种排序方法 ${ }^{[14]}$. 在 RDA 分析过程中, 运用蒙特卡罗检验分析评价环境因子对鱼类功能群结 构变化影响的显著程度. 
使用 SPSS 20 软件对相关数据进行统计处理, 差异性分析显著性水平为 $\alpha=0.05$. 使用 PRIMER 5.2、 CANOCO 4.5、ArcGIS 10.1 软件绘图.

\section{2 结果与分析}

\section{1 东太湖鱼类功能群构建和组成}

2.1.1 东太湖渔获物分析 调查结果显示, 东太湖共收集渔获物 42 种, 其中鱼类 39 种, 虾蟹类 3 种. 鱼类分 属于 4 目 10 科 31 属. 其中鲤形目 27 种, 占比 $69.23 \%$. 科的水平上看, 鲤科鱼类优势明显, 有 26 种, 占比 $66.67 \%$, 其他各科种类数均不超过 3 种. 4 个监测点的鱼类物种数季节变化明显, 4 月份物种数最高, 共监测 到鱼类 32 种, 7 月、 10 月逐渐降低, 分别监测到鱼类 25 种、18 种. 空间上来看, 原网围养殖区共采集到鱼类 32 种, 非养殖区共采集到 31 种. 红鯺原鲌(Cultrichthys erythropterus)、鲫(Carassius auratus)、大鯺鱊 (Acheilognathus macropterus)、兴凯鱊(Acheilognathus chankaensis)、粲(Hemiculter leucisculus)、刀鲚(Coilia nasus)、长须 黄滪鱼 (Pelteobagrus eupogon)、鳙( Aristichthys nobilis)、麦穗鱼 (Pseudorasbora parva) 是最常见物种, 在 4 个监 测点位所有季节采样中都有出现. 华鳈 (Sarcocheilichthys sinensis)、小黄點鱼 (Micropercops swinhonis)、圆尾斗 鱼 (Macropodus chinensis)、高体鳑鲏(Rhodeus ocellatus)、似鱎( Toxabramis swinhonis) 等出现频率较低, 仅在 1 个季节 1 个监测点出现, 为偶见种.

2.1.2 功能群 39 种鱼类可构成 4 个营养功能群: (1) 次级肉食性鱼类 (TG1), 包括: 乌鳢 (Channa argus)、河 川沙塘鳢 (Odontobutis potamophila)、攰嘴鲌(Culter alburnus)、鳜 (Siniperca chuatsi) 等 10 种鱼类; (2) 初级肉 食性鱼类(TG2), 包括刀鲚、棒花鱼 (Abbottina rivularis)、蛇鮈 (Saurogobio dabryi) 等 11 种鱼类; (3) 植食性鱼 类(TG3)，包括草鱼 (Ctenopharyngodon idellus)、鳊 (Parabramis pekinens)、似鳊 (Pseudobrama simoni)、银鲖 (Xenocypris argentea)、细鳞鲖 (Xenocypris microlepis)、兴凯䱻共 7 种鱼类; (4) 杂食性鱼类 (TG4), 包括鲤 (Cyprinus carpio)、鲫、粲 (Hemiculter leucisculus)、贝氏㛑 (Hemiculter bleekeri)、似刺鳊鮈 (Paracanthobrama guichenoti) 等共 11 种 (表 1 ).

聚类分析结果显示, 在相似性 96\% 时, 39 种鱼类可分为 5 大运动功能群 (分别为 LG1 LG5) (图 2). LG1、LG2、LG3 与 LG4、LG5 的组间差异性由 “最大尾鳍高/最小尾柄高”决定. LG1、LG2、LG3 的最大尾鳍高/ 最小尾柄高值范围为 $1.04 \sim 1.66$, 其游泳能力相对较弱, 而其组内相似性主要由 “体高/体长” 决定. LG1 组 “体高/体长” 值为 $0.13 \sim 0.22$, 对应的体型特征为圆筒型, 主要包括的鱼类有河川沙塘鳢、棒花鱼、鲤鱼、泥鲉 (Misgurnus anguillicaudatus)、子陵吻虾虎鱼 (Rhinogobius giurinus) 等 6 种. LG2 与 LG3 的体高/体长值为 $0.07 \sim 0.09$, 对应的体型特征为鳗型, 但 LG2 的“最大尾鯺高/最小尾柄高” 值为 1.04 , 其游泳能力相对较弱, 仅包含 1 个物种, 即须鳗虾虎鱼 (Taenioides cirratus); LG3 的“最大尾鯺高/最小尾柄高” 值达 1.66 , 其游泳能 力相对较强, 仅包含 1 个物种, 即中华刺䱊 (Mastacembelus sinensis). LG4、LG5 最大尾鯺高/最小尾柄高值范 围为 $1.61 \sim 3.20$, 游泳能力强, 其组内相似性主要由 “体高/体长” 决定. LG4 体高/体长值范围为 $0.17 \sim 0.18$, 对应体型为圆筒型, 包括了似鱎、华鳈、乌鳢 3 个物种; LG5 体高/体长值范围为 $0.18 \sim 0.41$, 对应体型特征为 纺锤型,包括草鱼、鲔、红鯺原鲌、似刺鳊鮈等 29 种鱼类.

根据鱼类的运动特征和营养特征来构建 39 种鱼类的 “运动一营养” 复合功能群, 共含 11 个复合功能群 (表 1), 分别是 CG1 功能群: 主要是初级肉食性、纺锤体型且运动能力强的鱼类 (简称初肉一强纺锤型功能 群), 包括刀鲚、鳙、麦穗鱼、花鳃(Hemibarbus maculatus)、蛇鮈、圆尾斗鱼共 6 种鱼类; CG2 功能群: 初级肉食 性、圆筒体型且运动能力强的鱼类 (简称初肉一强圆筒型功能群), 仅含似鱎 1 种鱼类; CG3 功能群: 初级肉食 性、圆筒体型且运动能力弱的鱼类 (简称初肉一弱圆筒型功能群), 包括棒花鱼、泥䱊 (Misgurnus anguillicaudatus)、子陵吻鰕虎鱼 (Rhinogobius giurinus) 3 种鱼类; CG4 功能群: 初级肉食性、鳗型且运动能力强鱼类(简 称初肉一强鳗型功能群), 仅包括中华刺鲉 (Mastacembelus sinensis) 1 种鱼类; CG5 功能群: 次级肉食性、纺锤 体型且运动能力强的鱼类 (简称次肉一强纺锤型功能群), 包括尧嘴鲌、蒙古鲌 (Culter mongolicus)、达氏鲌 (Culter dabryi)、红鯺原鲌、黄颞鱼 (Pelteobagrus fulvidraco)、长须黄滪鱼 (Pelteobagrus eupogon)、光泽黄颖鱼 (elteobagrus nitidus)、鳜 8 种鱼类; CG6 功能群: 次级肉食性、圆筒体型且运动能力弱的鱼类 (简称次肉一弱圆 筒型功能群), 仅包含河川沙塘鳢 1 种; CG7 功能群: 次级肉食性、圆筒体型且运动能力强的鱼类 (简称次肉一 


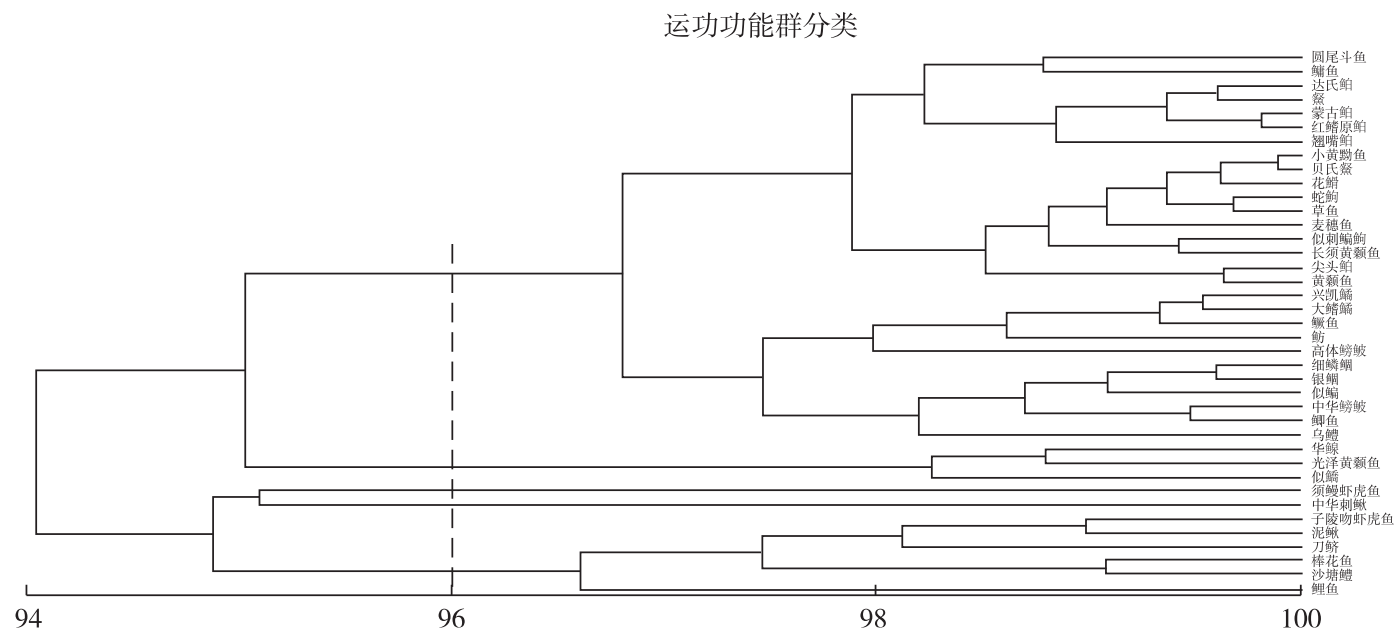

图 2 东太湖鱼类运动功能群聚类分析

Fig.2 The cluster analysis on locomotion groups of fish community in East Lake Taihu

强圆筒型功能群), 仅包含乌鳢 1 种; CG8 功能群: 植食性、纺锤体型且运动能力强的鱼类 (简称植食一强纺锤 型功能群), 包括草鱼、鳊、团头鲂 (Megalobrama amblycephala)、似鳊、银鲖、细鳞鲖、兴凯鱊 7 种鱼类; CG9 功 能群: 杂食性、纺锤体型且运动能力强的鱼类 (简称杂食一强纺锤型功能群), 包括鲫、粲、贝氏粲、大鳍鱊、中 华鳑鲔 (Rhodeus sinensis)、高体鳑鲏、华鳈、似刺鳊鮈、小黄䁫鱼共计 9 种鱼类; CG10 功能群: 杂食性、圆筒体 型且运动能力弱的鱼类 (简称杂食一弱圆筒型功能群), 仅包含鲤鱼 1 种; CG11 功能群: 杂食性、鳗型且运动 能力弱的鱼类 (简称杂食一弱鳗型功能群),仅包含须鳗虾虎鱼 (Taenioides cirratus) 1 种.

\section{2 东太湖鱼类功能群组成的时空变化特征}

原网围养殖区和非养殖区功能群种类数的时空变化如图 3a 所示. 从季节上看, 原网围养殖区 4-10 月 逐渐降低, 而非养殖区则呈现先降低后升高的变化趋势. 空间上看, 原网围养殖区功能群种类数在 4 月、7 月 分别达到了 9 种、7 种, 皆高于非养殖区; 10 月份时则呈现相反的情况, 原网围养殖区低于非养殖区.

原网围养殖区和非养殖区功能群组成时空变化如图 3b 所示. CG1、CG5、CG8、CG9 即初肉一强纺锤、次 肉一强纺锤、植食一强纺锤以及杂食一强纺锤功能群在每次监测中都有分布, 是东太湖鱼类功能群的主要组 成类型. CG2、CG11 即初肉一强圆筒、杂食一弱鳗型功能群仅在非养殖区的 1 次监测中出现,且所占比例很 小. 原网围养殖区中 CG9 杂食一强纺锤功能群所占比例最大, 其占比 $46.87 \% \sim 58.88 \%$, 平均占比 $51.94 \%$; 其 次为 CG1 初肉一强纺锤功能群 (占比 $11.29 \% \sim 25.93 \%$, 平均为 $19.86 \%$ )、CG5 次肉一强纺锤功能群(占比 $10.28 \% \sim 19.15 \%$, 平均为 $15.07 \%$ ) 以及 CG8 植食一强纺锤功能群 (占比 $3.74 \% \sim 22.22 \%$, 平均为 $11.49 \%$ ); 而 在非养殖区, CG1 初肉一强纺锤功能群的所占比例最大 (占比 $19.86 \% \sim 72.12 \%$, 平均为 $53.91 \%$ ), 其次为 CG9 杂食一强纺锤功能群 (占比 5.49\% 51.94\%, 平均为 $24.36 \%$ )、CG5 次肉一强纺功能群 (占比 $11.62 \%$ $15.75 \%$, 平均为 $14.15 \%$ ) 以及 CG8 植食一强纺锤功能群 (占比 1.16\% 11.49\%, 平均为 5.63\%). 从季节变化 上看, 4- 10 月原网围养殖区 CG9 杂食一强纺锤功能群占比基本稳定, 变化幅度不大, 但 CG5 次肉一强纺锤、 CG8 植食一强纺锤功能群逐渐减少, CG1 初肉一强纺锤占比逐渐升高; 非养殖区呈现 CG8 植食一强纺锤功能 群、CG9 杂食一强纺锤功能群占比大幅降低, CG1 初肉一强纺锤功能群占比大幅升高的现象. 同时 10 月份非 养殖区比原网围养殖区新增 CG2 初肉一强鳗型功能群、CG7 次肉一强圆筒功能群、CG10 杂食一弱圆筒功能 群共 3 个功能群. 但双因子交互相似性分析 (Two-way ANOVA) 表明, 原网围养殖区和非养殖区功能群组成 随季节、地点的变化并不显著 $(P=0.998,0.053)$. Simper 分析表明, 原网围养殖区、非养殖区功能群组成的 平均相似性分别为 $74.37 \%$ 、76.51\%, 主要组成类型为 CG9、CG8、CG5、CG1, 其累计贡献率均超过 $90 \%$. 
表 1 东太湖鱼类种类与营养、运动、复合功能群类型

Tab.1 The composition of species, trophic groups, locomotion groups and the combined groups for fish community in East Lake Taihu

\begin{tabular}{|c|c|c|c|c|}
\hline 种类 & 营养功能群 & 运动功能群 & $\begin{array}{l}\text { 营养一运动 } \\
\text { 复合功能群 }\end{array}$ & $\begin{array}{c}\text { 功能群 } \\
\text { 编号 }\end{array}$ \\
\hline \multicolumn{5}{|l|}{ 鲱形目 Clupeiformes } \\
\hline \multicolumn{5}{|l|}{ 鳀科 Engraulidae } \\
\hline 刀鲚 Coilia nasus & 初级肉食性 & 运动能力强, 纺锤体型 & 初肉-强纺锤 & CG1 \\
\hline \multicolumn{5}{|l|}{ 鲤形目 Cypriniformes } \\
\hline \multicolumn{5}{|l|}{ 鲤科 Cyprinidae } \\
\hline 草鱼 Ctenopharyngodon idellus & 植食性 & 运动能力强, 纺锤体型 & 植食-强纺锤 & CG8 \\
\hline 鳙 Aristichthys nobilis & 初级肉食性 & 运动能力强, 纺锤体型 & 初肉-强纺锤 & CG1 \\
\hline 鲤 Cyprinus carpio & 杂食性 & 运动能力弱, 圆通体型 & 杂食-弱圆筒 & CG10 \\
\hline 鲫 Carassius auratus & 杂食性 & 运动能力强, 纺锤体型 & 杂食-强纺锤 & CG9 \\
\hline 粲 Hemiculter leucisculus & 杂食性 & 运动能力强, 纺锤体型 & 杂食-强纺锤 & CG9 \\
\hline 贝氏粲 Hemiculter bleekeri & 杂食性 & 运动能力强, 纺锤体型 & 杂食-强纺锤 & CG9 \\
\hline 尧嘴鲌 Culter alburnus & 次级肉食性 & 运动能力强, 纺锤体型 & 次肉-强纺锤 & CG5 \\
\hline 蒙古鲌 Culter mongolicus & 次级肉食性 & 运动能力强, 纺锤体型 & 次肉-强纺锤 & CG5 \\
\hline 达氏鲌 Culter dabryi & 次级肉食性 & 运动能力强, 纺锤体型 & 次肉-强纺锤 & CG5 \\
\hline 红鯺原鲌 Cultrichthys erythropterus & 次级肉食性 & 运动能力强, 纺锤体型 & 次肉-强纺锤 & CG5 \\
\hline 鳊 Parabramis pekinens & 植食性 & 运动能力强, 纺锤体型 & 植食-强纺锤 & CG8 \\
\hline 似鱎 Toxabramis swinhonis & 初级肉食性 & 运动能力强, 圆筒体型 & 初肉-强圆筒 & CG2 \\
\hline 团头鲂 Megalobrama amblycephala & 植食性 & 运动能力强, 纺锤体型 & 植食-强纺锤 & CG8 \\
\hline 似鳊 Pseudobrama simoni & 植食性 & 运动能力强, 纺锤体型 & 植食-强纺锤 & CG8 \\
\hline 银鲖 Xenocypris argentea & 植食性 & 运动能力强, 纺锤体型 & 植食-强纺锤 & CG8 \\
\hline 细鳞鲖 Xenocypris microlepis & 植食性 & 运动能力强, 纺锤体型 & 植食-强纺锤 & CG8 \\
\hline 大鯺鱊 Acheilognathus macropterus & 杂食性 & 运动能力强, 纺锤体型 & 杂食-强纺锤 & CG9 \\
\hline 兴凯鱊Acheilognathus chankaensis & 植食性 & 运动能力强, 纺锤体型 & 植食-强纺锤 & CG8 \\
\hline 中华鰟鲏 Rhodeus sinensis & 杂食性 & 运动能力强, 纺锤体型 & 杂食-强纺锤 & CG9 \\
\hline 高体鳑鮍 Rhodeus ocellatus & 杂食性 & 运动能力强, 纺锤体型 & 杂食-强纺锤 & CG9 \\
\hline 麦穗鱼 Pseudorasbora parva & 初级肉食性 & 运动能力强, 纺锤体型 & 初肉-强纺锤 & CG1 \\
\hline 棒花鱼 Abbottina rivularis & 初级肉食性 & 运动能力弱, 圆筒体型 & 初肉-弱圆筒 & CG3 \\
\hline 花䱻 Hemibarbus maculatus & 初级肉食性 & 运动能力强, 纺锤体型 & 初肉-强纺锤 & CG1 \\
\hline 蛇鮈 Saurogobio dabryi & 初级肉食性 & 运动能力强, 纺锤体型 & 初肉-强纺锤 & CG1 \\
\hline 华鳈 Sarcocheilichthys sinensis & 杂食性 & 运动能力强, 纺锤体型 & 杂食-强纺锤 & CG9 \\
\hline 似刺鳊鮈 Paracanthobrama guichenoti & 杂食性 & 运动能力强, 纺锤体型 & 杂食-强纺锤 & CG9 \\
\hline \multicolumn{5}{|l|}{ 鳅科 Cobitidae } \\
\hline 泥鱾 Misgurnus anguillicaudatus & 初级肉食性 & 运动能力弱, 圆筒体型 & 初肉-弱圆筒 & CG3 \\
\hline \multicolumn{5}{|l|}{ 鲇形目 Siluriformes } \\
\hline \multicolumn{5}{|l|}{ 鲿科 Bagridae } \\
\hline 黄颡鱼 Pelteobagrus fulvidraco & 次级肉食性 & 运动能力强, 纺锤体型 & 次肉-强纺锤 & CG5 \\
\hline 长须黄颡鱼 Pelteobagrus eupogon & 次级肉食性 & 运动能力强, 纺锤体型 & 次肉-强纺锤 & CG5 \\
\hline 光泽黄颡鱼 Pelteobagrus nitidus & 次级肉食性 & 运动能力强, 纺锤体型 & 次肉-强纺锤 & CG5 \\
\hline \multicolumn{5}{|l|}{ 鲈形目 Perciformes } \\
\hline \multicolumn{5}{|l|}{ 虾虎鱼科 Gobiidae } \\
\hline 子陵吻虾虎鱼 Rhinogobius giurinus & 初级肉食性 & 运动能力弱, 圆筒体型 & 初肉-弱圆筒 & CG3 \\
\hline 须鳗虾虎鱼 Taenioides cirratus & 杂食性 & 运动能力弱, 撸型体型 & 杂食-弱鳗型 & CG11 \\
\hline \multicolumn{5}{|l|}{ 塘鳢鱼科 Eleotridae } \\
\hline 河川沙塘鳢 Odontobutis potamophila & 次级肉食性 & 运动能力弱, 圆筒体型 & 次肉-弱圆筒 & CG6 \\
\hline 小黄䁫鱼 Micropercops swinhonis & 杂食性 & 运动能力强, 纺锤体型 & 杂食-强纺锤 & CG9 \\
\hline \multicolumn{5}{|l|}{ 斗鱼科 Belontiidae } \\
\hline 圆尾斗鱼 Macropodus chinensis & 初级肉食性 & 运动能力强, 纺锤体型 & 初肉-强纺锤 & CG1 \\
\hline
\end{tabular}


续表 1

\begin{tabular}{|c|c|c|c|c|}
\hline 种类 & 营养功能群 & 运动功能群 & $\begin{array}{l}\text { 营养一运动 } \\
\text { 复合功能群 }\end{array}$ & $\begin{array}{c}\text { 功能群 } \\
\text { 编号 }\end{array}$ \\
\hline \multicolumn{5}{|l|}{ 月鳢科 Channidae } \\
\hline 乌鳢 Channa argus & 次级肉食性 & 运动能力强, 圆筒体型 & 次肉-强圆筒 & CG7 \\
\hline \multicolumn{5}{|l|}{ 刺鳅科 Mastacembelidae } \\
\hline 中华刺鱾 Mastacembelus sinensis & 初级肉食性 & 运动能力强, 鳗型体型 & 初肉-强鳗型 & CG4 \\
\hline \multicolumn{5}{|l|}{ 鮨科 Serranidae } \\
\hline 鲊 Siniperca chuatsi & 次级肉食性 & 运动能力强, 纺锤体型 & 次肉-强纺锤 & CG5 \\
\hline
\end{tabular}

(a)

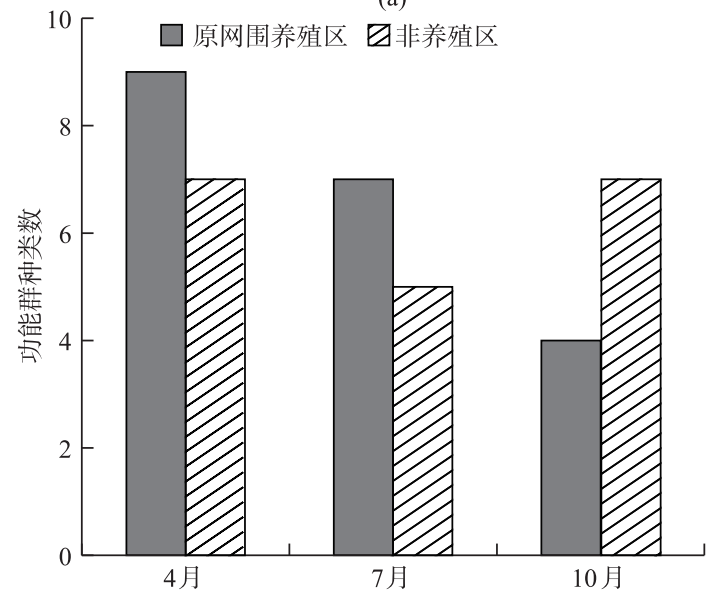

(b)

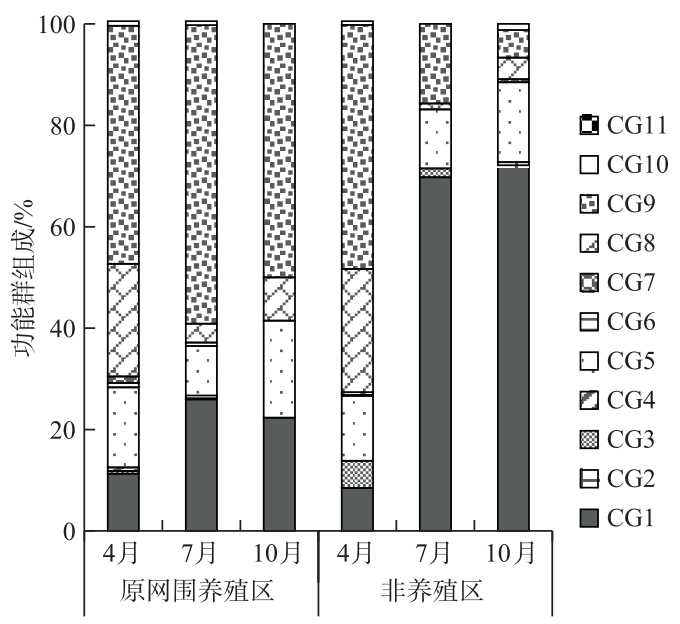

图 3 东太湖鱼类功能群种类数 (a) 和组成 (b) 时空变化分布

Fig.3 The spatio-temporal variation of species number (a) and composition (b) for combined functional groups of fish community in East Lake Taihu

单位捕捞努力量渔获量 (CPUE) 可以用来表 征资源密度状况, 从 CPUE 指标来看, CG1 CG4、 CG11 在非养殖区的密度高于原网围养殖区, 而 CG5 CG10 功能群的密度则为原网围养殖区高于 非养殖区, 可以看出初级肉食性鱼类较多分布于 非养殖区 (表 2), 而杂食性、次级肉食性和植食性 鱼类多分布于原网围养殖区. 因监测数据不符合 正态分布, 故选择非参数 Kruskal-Wallis 单因素检 验对各功能群在原网围养殖区和非养殖区的密度 进行对比分析. 结果表明, 各功能群密度在原网围 养殖区与非养殖区并无显著性差异 $(P>0.05)$.

\section{3 东太湖鱼类功能群结构与环境因子的关系}

DCA 排序结果如表 3 所示, 原网围养殖区第 一轴最长为 1.007 , 解释的物种变化率为 $50.20 \%$; 非养殖区第一轴最长为 1.230 , 解释的物种变化率 为 $45.10 \%$, 两个水域 4 个排序轴的长度均小于 3 , 因此东太湖鱼类功能群结构对环境因子的响应呈
表 2 东太湖原网围养殖区与非养殖区 各功能群 CPUE 对比

Tab.2 Comparisons on CPUE for combined groups of fish community in the original net enclosure and no net enclosure areas in East Lake Taihu

\begin{tabular}{cccc}
\hline \multirow{2}{*}{ 功能群 } & \multicolumn{2}{c}{ CPUE/ (ind./ $($ net·12 h) } & \multirow{2}{*}{$P$ 值 } \\
\cline { 2 - 3 } & 原网围养殖区 & 非养殖区 & \\
\hline CG1 & $65.00 \pm 45.03$ & $133.33 \pm 100.27$ & 0.275 \\
CG2 & $/$ & $0.33 \pm 0.58$ & 0.317 \\
CG3 & $1.33 \pm 1.52$ & $10.67 \pm 13.62$ & 0.376 \\
CG4 & $1.33 \pm 2.31$ & $/$ & 0.317 \\
CG5 & $500.00 \pm 35.38$ & $42.67 \pm 18.15$ & 0.827 \\
CG6 & $2.67 \pm 2.52$ & $0.33 \pm 0.58$ & 0.246 \\
CG7 & $2.33 \pm 4.04$ & $0.33 \pm 0.58$ & 0.796 \\
CG8 & $49.33 \pm 64.78$ & $43.67 \pm 66.12$ & 0.275 \\
CG9 & $187.00 \pm 121.34$ & $98.67 \pm 118.49$ & 0.275 \\
CG10 & 1.00 & $0.67 \pm 1.15$ & 0.637 \\
CG11 & $/$ & $0.33 \pm 0.58$ & 0.317 \\
\hline
\end{tabular}

/代表未监测到此功能群. 
线性关系,适用线性模型.

表 3 原网围养殖区、非养殖区鱼类复合功能群的 DCA 分析结果

Tab.3 Results of DCA analysis on combined groups in the original net enclosure and no net enclosure areas

\begin{tabular}{|c|c|c|c|c|c|c|c|c|}
\hline & \multicolumn{4}{|c|}{ 原网围养殖区 } & \multicolumn{4}{|c|}{ 非养殖区 } \\
\hline & 轴 1 & 轴 2 & 轴 3 & 轴 4 & 轴 1 & 轴 2 & 轴 3 & 轴 4 \\
\hline 特征值 & 0.154 & 0 & 0 & 0 & 0.187 & 0.084 & 0 & 0 \\
\hline 梯度长度 & 1.007 & 0 & 0 & 0 & 1.230 & 0.870 & 0 & 0 \\
\hline 物种数据累计百分比 $/ \%$ & 50.2 & 0 & 0 & 0 & 45.1 & 65.3 & 0 & 0 \\
\hline
\end{tabular}

对原网围养殖区和非养殖区的鱼类功能群结构进行 PCA 分析 (表 4), 前两轴为主成分轴, 分别解释了 原网围养殖区与非养殖区 $81.2 \%$ 和 $77.9 \%$ 的功能群结构变化,12 个环境因子的变化能解释 $98.4 \% \sim 99.4 \%$ 的 鱼类功能群的总变化. 同时再做 RDA 分析, 并分别做功能群一环境因子的排序图 4. 可以看出在原网围养殖 区氨氮与第二轴负相关较强; 在非养殖区 $\mathrm{pH}$ 与第一轴负相关较强.

表 4 原网围养殖区、非养殖区鱼类复合功能群的 PCA 分析结果

Tab.4 Results of PCA analysis on combined groups in the original net enclosure and no net enclosure areas

\begin{tabular}{|c|c|c|c|c|c|c|c|c|}
\hline \multirow{2}{*}{ 指标 } & \multicolumn{4}{|c|}{ 原网围养殖区 } & \multicolumn{4}{|c|}{ 非养殖区 } \\
\hline & 轴 1 & 轴 2 & 轴 3 & 轴 4 & 轴 1 & 轴 2 & 轴 3 & 轴 4 \\
\hline 特征值 & 0.594 & 0.218 & 0.110 & 0.062 & 0.594 & 0.185 & 0.137 & 0.078 \\
\hline 物种和环境因子排序轴相关系数 & 1.000 & 1.000 & 1.000 & 1.000 & 1.000 & 1.000 & 1.000 & 1.000 \\
\hline 物种数据累计百分比/\% & 59.4 & 81.2 & 92.1 & 98.4 & 59.4 & 77.9 & 91.7 & 99.4 \\
\hline 物种和环境关系累计百分比 $/ \%$ & 59.4 & 81.2 & 92.1 & 98.4 & 59.4 & 77.9 & 91.7 & 99.4 \\
\hline
\end{tabular}
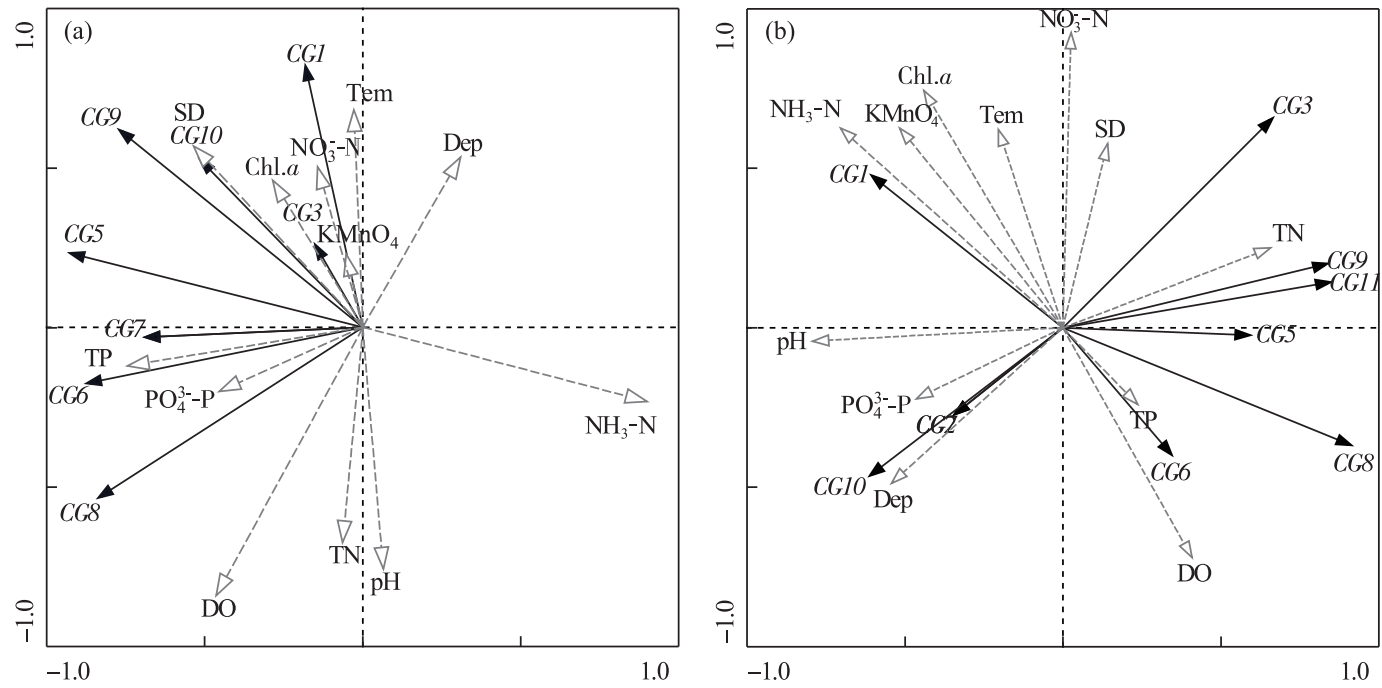

图 4 东太湖原网围养殖区 (a)、非养殖区 (b) 鱼类复合功能群与环境因子的 RDA 双序图

Fig.4 RDA graph of combined groups and environment factors in the original net enclosure(a) and no net enclosure(b) areas in East Lake Taihu

$\mathrm{RDA}$ 分析研究结果表明 (表 5), 在原网围养殖区, $\mathrm{NH}_{3}-\mathrm{N}$ 对主要功能群组成变化的解释量为 $49.80 \%$, 是显著影响因子 (蒙特卡罗检验 $P=0.02$ ). 所有功能群的数量变动都与 $\mathrm{NH}_{3}-\mathrm{N}$ 呈较强的负相关关系. 其他 
因子中 DO、Chl. $a 、 \mathrm{TN} 、 \mathrm{TP}$ 对功能群数量变动解释量贡献率相对较大, 其中 Chl. $a$ 、 TP 与所有功能群数量变动 呈正相关关系; DO 、TN 与 CG5、CG6、CG7、CG8 呈正相关, 与其他功能群呈负相关. 但蒙特卡罗检验表明,除 氨氮外其他环境因子对鱼类功能群的解释并不显著 $(P>0.05)$. 对于非养殖区, $\mathrm{pH}$ 是主要影响因子, 其对功 能群组成变化的解释量为 $41.80 \%$; 其次为 $\mathrm{TP} 、 \mathrm{NO}_{3}^{-}-\mathrm{N} 、 \mathrm{PO}_{4}^{3-}-\mathrm{P} 、 \mathrm{TN} . \mathrm{pH}$ 与 $\mathrm{CG} 1 、 \mathrm{CG} 2 、 \mathrm{CG} 10$ 功能群数量变动呈 正相关关系, 与其他功能群呈负相关关系, 而 TP 与除 $\mathrm{CG} 1$ 外的其他功能群呈正相关关系, $\mathrm{NO}_{3}^{-}-\mathrm{N}$ 、 $\mathrm{TN}$ 与多 数功能群呈正相关, $\mathrm{PO}_{4}^{3-}-\mathrm{P}$ 与多数功能群呈负相关. 但所有因子对非养殖区鱼类功能群的解释并不显著 $(P>0.05)$.

表 5 复合功能群与主要环境因子 RDA 分析结果

Tab.5 Results of RDA analysis on combined groups and environment factors

\begin{tabular}{|c|c|c|c|c|c|}
\hline \multicolumn{3}{|c|}{ 原网围养殖区 } & \multicolumn{3}{|c|}{ 非养殖区 } \\
\hline 环境因子 & 解释量/\% & 显著性检验 $(P)$ & 环境因子 & 解释量 $/ \%$ & 显著性检验 $(P)$ \\
\hline $\mathrm{NH}_{3}-\mathrm{N}$ & 49.80 & $0.02^{*}$ & $\mathrm{pH}$ & 41.80 & 0.11 \\
\hline DO & 23.40 & 0.14 & $\mathrm{TP}$ & 22.40 & 0.21 \\
\hline Chl. $a$ & 12.60 & 0.18 & $\mathrm{NO}_{3}^{-}-\mathrm{N}$ & 18.80 & 0.23 \\
\hline $\mathrm{TN}$ & 10.30 & 0.25 & $\mathrm{PO}_{4}^{3-}-\mathrm{P}$ & 14.20 & 0.17 \\
\hline $\mathrm{TP}$ & 3.90 & 0.76 & $\mathrm{TN}$ & 2.70 & 1.00 \\
\hline 其他因子 & $<1$ & / & 其他因子 & $<1$ & / \\
\hline
\end{tabular}

$*$ 为显著影响因子 $(P<0.05), /$ 代表未做显著性检验.

\section{3 讨论}

本研究中, 在网围拆除后东太湖调查监测到鱼类 39 种, 与网围拆除前相比 ${ }^{[22]}$, 东太湖鱼类种类数增长 较多; 但种类数仍低于 2007 年以及 $2009-2010$ 年的全太湖鱼类调查结果 (分别为 $60 、 50$ 种) ${ }^{[26-27]}$. 鱼类组 成中鲤科鱼类种类数占比 $66.67 \%$, 与太湖相当 $(66 \%)$. 太湖中常见的间下鱵、大银鱼、陈氏短吻银鱼、鲢等 种类并未在东太湖的年度监测中出现, 表明东太湖的鱼类群落仍然需要时间进行恢复.

与常规物种多样性评估手段相比, 鱼类功能群研究的优势是可以协助定向理解和解析鱼类群落对地理 环境变化以及干扰活动的功能响应 ${ }^{[28-30]}$. 本研究中, 东太湖鱼类可构建成 11 个 “营养一运动功能群”, 其主 要功能群类型为 “杂食一强纺锤”功能群, 占比为 $41.34 \%$. 此与新安江流域中鱼类功能群组成具有一定相似 性 ${ }^{[31]}$. 杂食性表明鱼类摄食范围较广, 而纺锤体型则在水中阻力较小, 游泳能力强, 身避天敌及获取食物的 能力较强 ${ }^{[32]}$. 鱼类功能群组成中以 “杂食一强纺锤”功能群占优势, 体现了鱼类对东太湖地理环境的适应策 略 ${ }^{[31]}$. 鱼类功能群组成的时空变化一定程度上也表明了鱼类功能群对网围拆除的响应过程 ${ }^{[18,33]}$. 在网围拆 除后原网围养殖区鱼类群落恢复较快, 其功能群种类数在 4 月、7 月时高于非养殖区, 而在组成类型上一直 以“CG9 杂食一强纺锤”功能群为主. 这主要是与网围拆除后阻隔效应的消失以及原网围养殖区营养物质残 留有关 ${ }^{[34]}$. 网围拆除后, 鱼类的生存活动空间扩大, 同时原网围养殖区的沉积物中碎屑及投㙁残留尤其是 动物性饲料残留较多, 吸引了杂食性、肉食性鱼类的受食和聚集 ${ }^{[21,35]}$. 因此杂食性、次级肉食性鱼类功能群 密度呈现原网围养殖区 > 非养殖区. 与原网围养殖区相比, 非养殖区鱼类群落恢复较慢, 功能群种类数少, 并 且功能群组成变化较大. 4- 10 月非养殖区“CG9 杂食一强纺锤”功能群的占比下降 46.48\%, “CG1 初肉一强 纺锤”功能群占比升高 $63.65 \%$, 尤其是刀魰数量占比从 $7.32 \%$ 上升至 $67.88 \%$, 组成类型逐渐从 “CG9 杂食一 强纺锤 $+\mathrm{CG} 8$ 植食一强纺锤”转变为以 “ CG1 初肉一强纺锤” 功能群为主. 这可能与网围拆除后东太湖浮游动 物的空间分布有关 ${ }^{[36-37]}$. 监测发现 7-10 月, 非养殖区浮游动物生物量为 $0.37 \sim 0.92 \mathrm{mg} / \mathrm{L}$, 原网围养殖区生 物量为 $0.09 \sim 0.22 \mathrm{mg} / \mathrm{L}$, 非养殖区浮游动物生物量远高于原网围养殖区, 为浮游动物食性的刀鲚提供更多 的饵料. 总体来看, 东太湖网围拆除后原网围养殖区食物来源稳定, 栖息环境适宜, 鱼类功能群组成类型多 样且相对稳定; 而非养殖区鱼类功能群种类少且组成类型季节变化较大, 功能群组成趋向单一化. 对比显示 拆除网围对东太湖鱼类群落恢复及生态系统功能修复具有一定的积极作用, 但值得注意的是非养殖区乃至 
整个东太湖鱼类群落是否会像太湖一样呈现单一化、小型化的演变趋势需要引起关注和重视 ${ }^{[27]}$, 应进行长 期连续的监测和研究.

鱼类群落空间分布受环境因子空间异质性的影响较大, 总磷、总氮、叶绿素 $a$ 、透明度、水深、水温、 $\mathrm{pH}$ 、 溶解氧、空间距离等都是影响鱼类群落结构的主要环境因子 ${ }^{[38-40]}$, 这些因素同样也对鱼类功能群时空分布 产生影响. 本文通过 RDA 分析结果显示氨氮是影响东太湖鱼类功能群分布的显著影响因子, 并且与所有功 能群呈显著负相关关系. 这可能与东太湖网围拆除后水生植物的分布有关. 遥感监测显示, 网围拆除后原网 围养殖区水生植被由沉水植物为主向浮叶植物为主转变, 生物量暴发式增长 ${ }^{[41]}$. 这些水生植物在秋季后随 着温度下降逐渐衰亡, 向水体释放大量氮、磷等营养物质导致水体氨氮浓度显著上 升 $^{[42]}$. 4-10 月份, 原网 围养殖区氨氮浓度由 $0.08 \mathrm{mg} / \mathrm{L}$ 上升至 $0.68 \mathrm{mg} / \mathrm{L}$. 按照《渔业水质标准》( GB 1107-1989) 中总氨换算表对 氨氮进行换算 ${ }^{[43]}, 10$ 月份时原网围养殖区非离子氨浓度达到 $0.03 \mathrm{mg} / \mathrm{L}$, 超过《渔业水质标准》中非离子氨 浓度不超过 $0.02 \mathrm{mg} / \mathrm{L}$ 的标准. 氨氮对鱼类的生长、繁殖有较大的负面影响, 浓度较高会造成鱼类中毒死亡. 原网围养殖区氨氮浓度升高,栖息环境恶化,鱼类逃避行为明显 ${ }^{[44]}$. 水体的 $\mathrm{pH}$ 值过高或过低也会影响鱼类 的新陈代谢、生长发育以及呼吸生理等一系列过程 ${ }^{[45]}$, 同时会影响到浮游生物的分布. 东太湖浮游动物的 分布与 $\mathrm{pH}$ 呈负相关关系 ${ }^{[46]}$, 非养殖区 $\mathrm{pH}$ 从春季至秋季逐渐降低, 浮游动物密度逐渐升高, 导致了以浮游 动物为食物来源的初级肉食性鱼类的增加 (如刀鲚等), 所以 $\mathrm{pH}$ 与 “ $\mathrm{CG} 1$ 初肉一强纺锤” “ $\mathrm{CG} 2$ 初肉一强圆 筒” 功能群呈正相关. TP、Chl. $a$ 、TN 基本与鱼类功能群呈正相关, 此与太子河流域的研究结果较为一致 ${ }^{[47]}$. 磷是太湖水质环境中的限制因子, 其对浮游生物的生长、繁殖的促进作用较为明显 ${ }^{[37]}$, 进而为鱼类带来丰富 的食物来源. 但除氨氮外, 其他环境因子与鱼类功能群的相关性并不显著, 鱼类功能群与环境因子的相互关 系仍需更长时间尺度上的研究和探讨.

\section{4 结论}

网围拆除后东太湖监测到鱼类 39 种, 可构建成 11 个“营养一运动”复合功能群, 其中 “杂食一强纺锤” 功 能群占比最大, 比例为 $41.34 \%$. 原网围养殖区与非养殖区在功能群组成及空间分布上具有明显差异, 原网 围养殖区鱼类功能群类型多样但以 “杂食一强纺锤” 鱼类功能群为主, 季节变化小; 非养殖区鱼类功能群类 型少并季节变化明显, 从春季到秋季则从“杂食一强纺锤” + “植食一强纺锤”为主向 “初肉一强纺锤”功能群 为主演变, 趋向单一化. 组成密度上原网围养殖区杂食性、次级肉食性、植食性鱼类功能群密度大于非养殖 区, 而初级肉食性功能群密度小于非养殖区. 环境因子中氨氮是影响原网围区鱼类功能群结构分布的显著 影响因子, 且与所有鱼类功能群分布呈负相关, 其可能与原网围区水生植被的衰亡分解有关. $\mathrm{pH} 、 \mathrm{TP} 、 \mathrm{TN}$ 、 DO 等也是影响鱼类功能群分布的主要环境因子, 但其影响并未达到显著水平. 鱼类功能群的分析表明原网 围养殖区在鱼类功能群类型、组成、季节变化以及资源密度上优于非养殖区, 说明网围拆除对东太湖鱼类群 落的恢复及生态系统修复具有积极作用, 但鱼类群落恢复及生态环境的修复是长期复杂的过程, 网围拆除 后东太湖鱼类群落及自然环境的演变需要长期连续的监测与研究.

\section{5 参考文献}

[ 1 ] Wu QL. On the sustainable development of fishery in east Taihu Lake. J Lake Sci, 2001, 13(4): 337-343. DOI: 10. 18307/20010407. [ 吴庆龙. 东太湖养殖渔业可持续发展的思考. 湖泊科学, 2001, 13(4) : 337-343.]

[ 2 ] Gu XH, Wang XR, Hu WP. Effect of fishery development on water environment and its eco-countermeasure in East Lake Taihu. Shanghai Environmental Science, 2003, 22(10): 702-704. [ 谷孝鸿, 王晓荣, 胡维平. 东太湖渔业发展对水环 境的影响及其生态对策. 上海环境科学, 2003, 22(10): 702-704.]

[ 3 ] Brown SC, Smith K, Batzer D. Macroinvertebrate responses to wetland restoration in northern New York. Environmental Entomology, 1997, 26(5) : 1016-1024. DOI: 10.1093/ee/26.5.1016.

[ 4 ] Beauger A, Lair N, Reyes-Marchant P et al. The distribution of macroinvertebrate assemblages in a reach of the River Allier (France), in relation to riverbed characteristics. Hydrobiologia, 2006, 571 (1) : 63-76. DOI: 10.1007/s10750-0060217-x.

[ 5 ] Han J, Zhang J, Song MM et al. Structure and seasonal changes of fish functional groups in Jinan region. Research of Envi- 
ronmental Sciences, 2018, 31(9) : 1537-1544. [ 韩洁, 张杰, 宋蒙蒙等. 济南市水域鱼类功能群结构及其季节性变 化. 环境科学研究, 2018, 31(9): 1537-1544.]

[ 6 ] Kellnreitner F, Pockberger M, Asmus H. Seasonal variation of assemblage and feeding guild structure of fish species in a boreal tidal basin. Estuarine, Coastal and Shelf Science, 2012, 108: 97-108. DOI: 10.1016/j.ecss.2011.02.020.

[ 7 ] Poff NL, Allan JD. Functional organization of stream fish assemblages in relation to hydrological variability. Ecology, 1995, 76(2) : 606-627. DOI: 10.2307/1941217.

[ 8 ] Walker B, Kinzig A, Langridge J. Original articles: Plant attribute diversity, resilience, and ecosystem function: The nature and significance of dominant and minor species. Ecosystems, 1999, 2(2) : 95-113. DOI: 10.1007/s100219900062.

[ 9 ] Kuczynski L, Legendre P, Grenouillet G. Concomitant impacts of climate change, fragmentation and non-native species have led to reorganization of fish communities since the 1980s. Global Ecology and Biogeography, 2018, 27(2) : 213-222. DOI: $10.1111 /$ geb.12690.

[10] Zhang B, Tang QS, Jin XS. Functional groups of fish assemblages and their major species at high trophic level in the East China Sea. Journal of Fishery Sciences of China, 2007, 14(6): 939-949. [张波, 唐启升, 金显仕. 东海高营养层次鱼 类功能群及其主要种类. 中国水产科学, 2007, 14(6) : 939-949.]

[11] Zhang B, Li ZY, Jin XS. Functional groups of fish assemblages and their major species in the Bohai Sea. Journal of Fisheries of China, 2012, 36(1) : 64-72. [ 张波, 李忠义, 金显仕. 渤海鱼类群落功能群及其主要种类. 水产学报, 2012, 36(1): 64-72.]

[12] Zhang B, Tang QS, Jin XS. Functional groups of communities and their major species at high trophic level in the Yellow Sea ecosystem. Acta Ecologica Sinica，2009，29(3)：1099-1111. [张波，唐启升，金显仕. 黄海生态系统高营养层次 生物群落功能群及其主要种类. 生态学报, 2009, 29(3) : 1099-1111.]

[13] Ren XM, Xu BD, Zhang CL et al. The composition of and variations in the trophic guilds of fish assem-blages in Haizhou Bay and adjacent waters. Journal of Fishery Sciences of China, 2019, 26(1) : 141-150. DOI: 10.3724/SP.J.1118.2019. 18149. [任晓明, 徐宾铎, 张崇良等. 海州湾及邻近海域鱼类群落的营养功能群及其动态变化. 中国水产科学, 2019, 26(1): 141-150.]

[14] Zhang D, Wan FY, Chu L et al. Longitudinal patterns in $\alpha$ and $\beta$ diversity of the taxonomic and functional organizations of stream fish assemblages in the Qingyi River. Biodiversity Science, 2018, 26(1) : 1-13. DOI: 10.17520/biods. 2017263. [张东, 宛风英, 储玲等. 青江鱼类分类群和功能群的 $\alpha$ 和 $\beta$ 多样性纵向梯度格局. 生物多样性, 2018, 26(1): $1-13$.

[15] Li LJ, Zhang J, Wu D et al. Relationships between structure and diversity of fish functional groups and land use in the Taizi River. Acta Ecologica Sinica, 2017, 37(20): 6863-6874. [李丽娟, 张吉, 吴丹等. 太子河流域鱼类功能群结构与 多样性对土地利用类型的响应. 生态学报, 2017, 37(20): 6863-6874.]

[16] Dumay O, Tari PS, Tomasini JA et al. Functional groups of lagoon fish species in Languedoc Roussillon, southern France. Journal of Fish Biology, 2004, 64(4) : 970-983. DOI: 10.1111/j.1095-8649.2004.00365.x.

[17] Bhele U, Öğlü B, Tuvikene A et al. How long-term water level changes influence the spatial distribution of fish and other functional groups in a large shallow lake. Journal of Great Lakes Research, 2020, 46(4) : 813-823. DOI: 10.1016/j.jglr. 20202.010.

[ 18 ] Xia ZJ, Jiang ZG, Xie H et al. Functional groups of fish community in the Huayang lake group and their response to enclosure culture. Chinese Journal of Ecology, 2018, 37(2) : 438-445. DOI: 10.13292/j.1000-4890.201802.006. [ 夏治俊, 蒋忠冠, 谢涵等. 华阳湖群鱼类功能群及其对围网养殖的响应. 生态学杂志, 2018, 37(2) : 438-445.]

[19] Wu QL, Chen KN, Gao G et al. Effects of pen fish culture on water environment and their countermeasure. Journal of Fisheries of China , 1995, 19(4) : 343-349. [ 吴庆龙, 陈开宁, 高光等. 大水面网围精养对水环境的影响及其对策. 水产学报, $1995,19(4): 343-349$. ]

[20] Li WC, Chen KN, Wu QL et al. A preliminary study on phosphorous saturation of the top sediment in East Taihu Lake. $J$ Lake Sci , 1998, 10(3) : 49-54. DOI: 10.18307/1998.0309. [李文朝, 陈开宁, 吴庆龙等. 东太湖表层沉积物的磷饱 和度初步研究. 湖泊科学, $1998, \mathbf{1 0}(3)$ : 49-54.]

[21] He J, Gu XH, Liu GF. Effect and optimization model of enclosure crab culture in East Lake Taihu. J Lake Sci, 2009, 21 (4) : 523-529. DOI : 10.18307/2009.0411. [何俊, 谷孝鸿, 刘国锋. 东太湖网围养蟹效应及养殖模式优化. 湖泊科 学, 2009, 21(4) : 523-529. ] 
[22] Li YK, Gong Y. Food web structure of the East Lake Taihu by analysis of stable carbon and nitrogen isotopes. Chinese Journal of Ecology, 2014, 33(6): 1534-1538. [李云凯, 贡艺. 基于碳、氮稳定同位素技术的东太湖水生食物网结构. 生 态学杂志, 2014, 33(6): 1534-1538.]

[23] Ni Y, Zhu CD eds. Fishes of Taihu Lake. Shanghai: Shanghai Scientific and Technical Publishers, 2005. [倪勇, 朱承德. 太湖鱼类志. 上海 : 上海科学技术出版社, 2005.]

[24] Ni Y, Wu HL eds. Fishes of Jiangsu Province. Beijing: China Agriculture Press, 2006. [倪勇, 伍汉霖. 江苏鱼类志. 北 京: 中国农业出版社, 2006.]

[25] Zhang JM, He ZH eds. Survey manual of fishery natural resources in inland waters. Beijing: Agriculture Press, 1991.[ 张 觉民, 何志辉. 内陆水域渔业自然资源调查手册. 北京: 农业出版社, 1991.]

[26] Zhu SQ, Liu ZW, Gu XH. Changes of the fish fauna and fish yield analysis in Lake Taihu. J Lake Sci, 2007, 19(6) : 664-669. DOI: 10.18307/2007.0607. [ 朱松泉, 刘正文, 谷孝鸿. 太湖鱼类区系变化和渔获物分析. 湖泊科学, $2007,19(6): 664-669$.

[27] Mao ZG, Gu XH, Zeng QF et al. Community structure and diversity of fish in Lake Taihu. Chinese Journal of Ecology, 2011, 30(12) : 2836-2842. DOI: 10.13292/j.1000-4890.2011.0435. [毛志刚, 谷孝鸿, 曾庆飞等. 太湖鱼类群落结 构及多样性. 生态学杂志, $2011,30(12): 2836-2842$. ]

[28] Lavorel S, McIntyre S, Landsberg J et al. Plant functional classifications: From general groups to specific groups based on response to disturbance. Trends in Ecology \& Evolution, 1997, 12(12) : 474-478. DOI: 10.1016/S0169-5347 (97) 01219-6.

[29] Lavorel S, McIntyre S, Grigulis K. Plant response to disturbance in a Mediterranean grassland: How many functional groups? Journal of Vegetation Science, 1999, 10(5) : 661-672. DOI: 10.2307/3237081.

[30] Aguilar-Medrano R, Durand JR, Cruz-Escalona VH et al. Fish functional groups in the San Francisco Estuary: Understanding new fish assemblages in a highly altered estuarine ecosystem. Estuarine, Coastal and Shelf Science, 2019, 227 : 106331. DOI: 10.1016/j.ecss.2019.106331.

[31] Chen B, Meng XC, Zhang D et al. Longitudinal patterns in taxonomic and functional organizations of fish assemblages in the Xin’an River. Acta Ecologica Sinica, 2019, 39(15) : 5730-5745. DOI: 10.5846/stxb201810072164. [陈兵, 孟雪晨, 张东等. 河流鱼类分类群和功能群的纵向梯度格局一以新安江流域为例. 生态学报, 2019, 39(15): 5730-5745.]

[32] Zhang HM, Gong SY. Study on body shape coefficient of common fish in reservoir. Freshwater Fisheries, 1983, 13(2): 14-18. [ 张海明, 龚世园. 水库常见鱼类体形系数的研究. 淡水渔业, 1983, 13(2): 14-18.]

[33] Brind'Amour A, Rochet MJ, Ordines F et al. Environmental drivers explain regional variation of changes in fish and invertebrate functional groups across the Mediterranean Sea from 1994 to 2012. Marine Ecology Progress Series, 2016, 562 : 19 35. DOI: $10.3354 / \operatorname{meps} 11912$.

[34] Yang ZF, Shi WG, Chen LQ et al. Ecological environment succession and countermeasure of East Taihu Lake. China Environmental Science, 2003, 23(1): 64-68. [杨再福, 施炜刚, 陈立侨等. 东太湖生态环境的演变与对策. 中国环境科 学, 2003, 23(1): 64-68.]

[35] Yang QX, Li WC. Environmental changes since foundation of pen-fish-farming in East Taihu Lake. China Environmental Science, 1996, 16(2) : 101-106. [杨清心, 李文朝. 东太湖围网养鱼后生态环境的演变. 中国环境科学, 1996, 16 (2) : 101-106.]

[36] Zeng X, Tang MZ, Cui D et al. Study on plant diversity in different human disturbance areas of Eastern Taihu Lake. Yangtze River, 2018, 49(3) : 41-44. [ 曾祥, 汤敏喆, 崔丹等. 东太湖不同人为干扰程度区域植物多样性研究. 人民长 江, 2018, 49(3): 41-44.]

[37] Li QQ, Huang HZ, Zhang QY et al. Annual variation of plankton in different water area of the East Taihu Lake and feeding habits of Hypophalmichthy molitrix and Aristichthys nobilis. Marine Sciences, 2013, 37(10): 104-110. [ 李倩倩, 黄鹤忠, 张群英等. 东太湖不同水域浮游生物周年变化及鲢、鳙食性的研究. 海洋科学, 2013, 37(10): 104-110. ]

[38] Kadye WT, Magadza CHD, Moyo NAG et al. Stream fish assemblages in relation to environmental factors on a montane plateau (Nyika Plateau, Malawi). Environmental Biology of Fishes, 2008, 83(4) : 417-428. DOI: 10.1007/s10641-0089364-4.

[39] Li J, Li XH, Jia XP et al. Relationship between fish community diversity and environmental factors in the Lianjiang River, 
Guangdong, China. Acta Ecologica Sinica, 2012, 32(18): 5795-5805. DOI: 10.5846/stxb201108041142. [李捷, 李新 辉, 贾晓平等. 连江鱼类群落多样性及其与环境因子的关系. 生态学报, 2012, 32(18): 5795-5805.]

[40] Zhang YQ, Huang DT, Li XH et al. Fish community structure and environmental effects of West River. South China Fisheries Science, 2020, 16(1): 42-52. [张迎秋, 黄稻田, 李新辉等. 西江鱼类群落结构和环境影响分析. 南方水产科 学, 2020,16(1): 42-52.]

[41] Yang JZC, Luo JH, Lu LR et al. Changes in aquatic vegetation communities based on satellite images before and after pen aquaculture removal in East Lake Taihu. J Lake Sci, 2021, 33(2) : 507-517. DOI : 10.18307/2021.0228. [ 杨井志成, 罗 菊花, 陆莉蓉等. 东太湖围网拆除前后水生植被群落遥感监测及变化. 湖泊科学, 2021, 33(2) : 507-517.]

[42] Wang YW, Xu J, Li JY et al. Changes of aquatic vegetation and water quality before and after complete dismantling of Seine net in East Taihu Lake. Journal of Ecology and Rural Environment, 2021. [王友文, 徐杰, 李继影等. 东太湖围 网全面拆除前后水生植被及水质变化. 生态与农村环境学报, 2021.]

[43] Water quality standard for fisheries (GB 11607-1989), 1990.[渔业水质标准( GB 11607-1989), 1990.]

[44] Li B, Fan QX, Yang K et al. Effects of chronic ammonia stress on foraging, growth, and haematological parameters of yellow catfish (Pelteobagrus fulvidraco) juveniles. Chinese Journal of Applied \& Environmental Biology, 2011, 17(6): 824-828. [李波, 柇启学, 杨凯等. 慢性氨氮胁迫对黄颡鱼摄食、生长及血液指标的影响. 应用与环境生物学报, $2011,17(6)$ : 824-828.]

[45] Li MD ed. Fish ecology. Tianjin: Tianjin Science and Technology Translation Publish Company, 1990: 31-32.

[46] Li LH, Wu JB, Lu XL et al. Preliminary study on seasonal succession of aquatic plants and algae inhibition effect in East Taihu Lake. Journal of Zhejiang Agricultural Sciences, 2016, 57 (2) : 288-291,293. [李灵慧, 吴建斌, 陆雪林等. 东太 湖水生植物季节演替及抑藻效应初探. 浙江农业科学, 2016, 57(2): 288-291,293.]

[47] Wang YT, Zhang Y, Gao X et al. Analysis of fish community distribution and its relationship with environmental factors in different freshwater eco-regions of taizi river basin. Research of Environmental Sciences, 2016, 29(2) : 192-201. [王云涛, 张远, 高欣等. 太子河流域不同水生态区鱼类群落分布与环境因子的关联性. 环境科学研究, 2016, 29(2): 192-201. ] 